\title{
Correction: Müll!
}

\section{Selbstbeschreibung und Textverfahren einer Skizze von Marie Netter}

\section{David-Christopher Assmann}

\section{Correction:}

Dtsch Vierteljahrsschr Literaturwiss Geistesgesch 2017

https://doi.org/10.1007/s41245-017-0044-0

Der Autor weist darauf hin, dass auf S. 419 im 2. Absatz der Ausdruck »Müll! --« im Original zentriert gesetzt ist. Diese Darstellung ist leider aus satztechnischen Gründen nicht möglich.

Der Verlag bittet dies zu entschuldigen.

Die Online-Version des Originalartikels ist unter https://doi.org/10.1007/s41245-017-0044-0 zu finden.

D.-C. Assmann $(\bowtie)$

Institut für deutsche Literatur und ihre Didaktik, Goethe-Universität Frankfurt,

Norbert-Wollheim-Platz 1, 60629 Frankfurt am Main, Deutschland

E-Mail: dc.assmann@em.uni-frankfurt.de 